\title{
The Epidural Treatment of Sciatica: Its Origin and Evolution
}

\author{
Bastiaan C. Ter Meulen ${ }^{a, c}$ Henry Weinstein ${ }^{a, c}$ Raymond Ostelo ${ }^{b}$ Peter J. Koehler ${ }^{d}$ \\ ${ }^{a}$ Department of Neurology, Onze Lieve Vrouwe Gasthuis, and ${ }^{b}$ Department of Health Sciences, VU University and EMGO

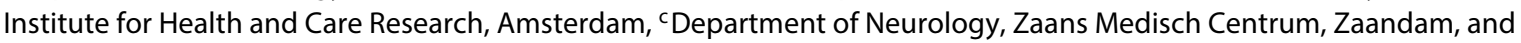 \\ ${ }^{\mathrm{d}}$ Department of Neurology, Atrium Medical Center, Heerlen, The Netherlands
}

\section{Key Words \\ Back pain · Sciatica · Pain treatment $\cdot$ Epidural injections . History $\cdot$ Corticosteroids $\cdot$ Debate}

\begin{abstract}
Epidural injection with corticosteroids is a common treatment option for patients with lower back pain or sciatica. In this paper we review its origin and evolution. The first injections were given around 1900 in Paris by Jean Sicard (18721929) and Fernand Cathelin (1873-1945), who worked independently. They both injected small volumes of cocaine into the sacral hiatus. After a slow start, the epidural treatment of back pain and sciatica gradually spread to other parts of Europe and Northern America. In the early 1950s, corticosteroids were introduced for epidural use. Since the 1970s, there have been numerous clinical trials that show a significant, although small, effect of epidural corticosteroid injections compared with placebo for leg pain in the short term. Despite an ongoing debate about effectiveness and safety, epidural injections remain popular. @2016 S. Karger AG, Basel
\end{abstract}

\section{Introduction}

Epidural injection with corticosteroids is a common treatment option for patients with lower back pain or sciatica [1]. The injections may offer rapid relief from pain in acute patients and may be a good treatment alternative for patients who for some reasons technically or motivationally, can or will not undergo spinal surgery. There is even a category of chronic pain patients who visit the pain clinic every couple of weeks to get repeated injections.

The first epidural injections were given around 1900 in Paris, not with corticosteroids, but with cocaine. In this paper, we trace the origins of the injections and how they evolved. Our interest is not so much in historical facts and figures for their own sake (out of curiosity), but to see how a common medical treatment evolved from a modest laboratory to a booming worldwide practice [2], despite an ongoing debate about effectiveness and safety. We refer to table 1 for a chronological overview.

\section{Two Minds but with a Single Thought?}

We are not sure who was the first to treat a patient with an epidural pain injection in the lower back. There are 2 claims. It is true that Jean-Anasthase Sicard (1872-1929) was the first to mention the injections publicly, when he addressed the members of the Societé de Biologie in Paris on April 20, 1901 [3]. However, at the time Sicard gave his speech, Fernand Cathelin (1873-1945), also from Paris, had been treating patients with epidural injections for some months already. Figure 1 shows their portraits. It is important to realize that both men were not inventors in the true sense. They simply perfected anesthetic tech-

\section{KARGER}

E-Mail karger@karger.com

www.karger.com/ene
(C) 2016 S. Karger AG, Basel

0014-3022/16/0752-0058\$39.50/0
Bastiaan C. Ter Meulen, MD

Department of Neurology

St. Lucas Andreas Hospital, Jan Tooropstraat 164

NL-1061 AE Amsterdam (The Netherlands)

E-Mail bas.termeulen@olvg.nl 

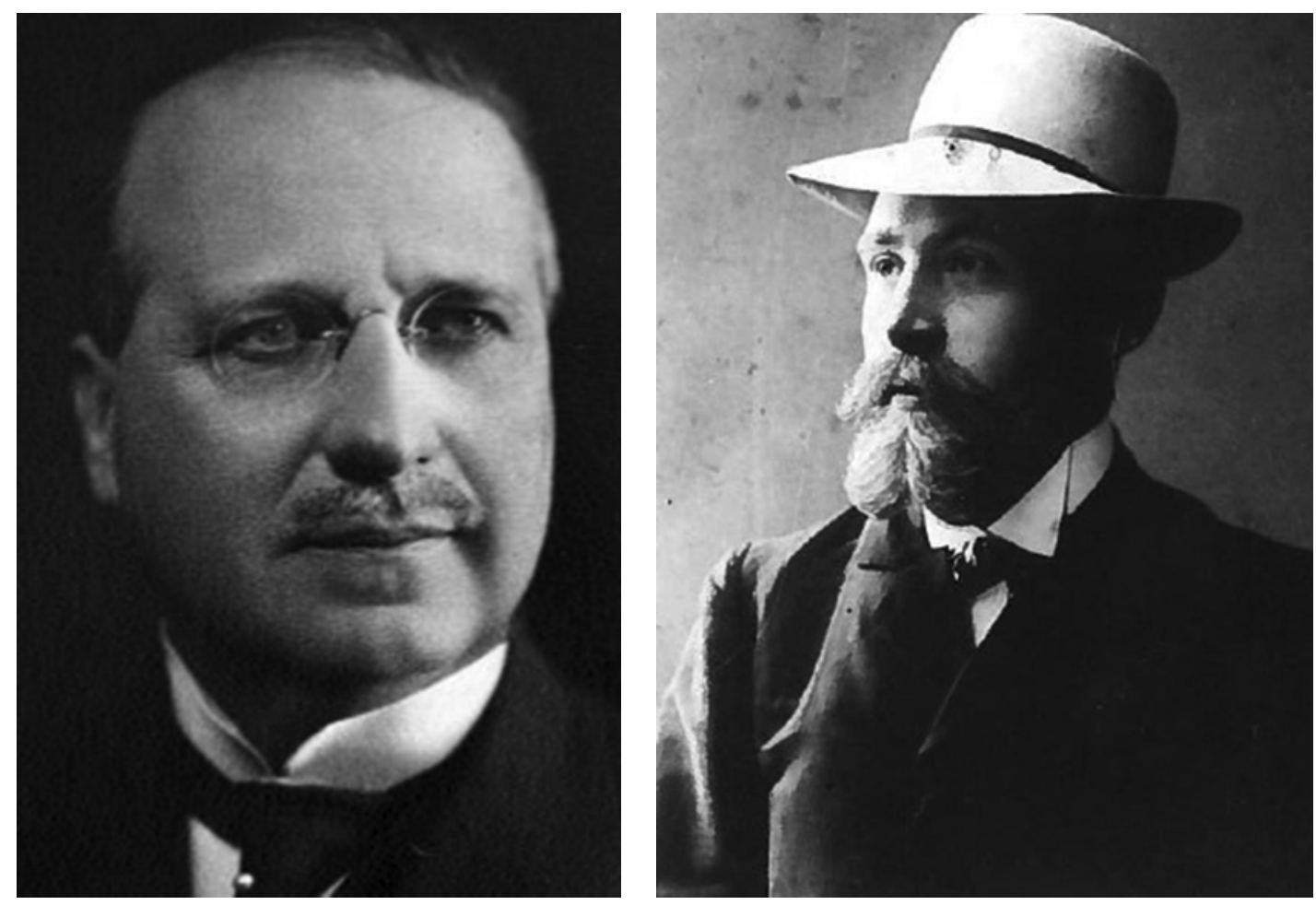

Fig. 1. Two minds but with a single thought? Sicard (left) and Cathelin presented their data on epidural injections against low back pain and sciatica almost at the same time.

Table 1. Timeline of the epidural treatment of sciatica

\begin{tabular}{lll}
\hline Year & Country & Description \\
\hline 1885 & USA & First spinal puncture by Corning \\
1895 & Germany & Intrathecal infusion of cocaine by Bier \\
1901 & France & First caudal epidural injections by Sicard and Cathelin \\
1925 & Canada & Viner uses novocain to treat sciatica \\
1930 & UK & Evans successfully treats 24/40 patients with procaine \\
1952 & Italy & Robecchi and Capra use corticosteroids for the first time \\
1953 & France & Lièvre et al. [21] publish a series of patients treated with epidural corticosteroids \\
1961 & USA & Goebert et al.: first series in the USA \\
1960 s-1970s & & Uncontrolled studies \\
1970 s-now & & Randomized, controlled trials \\
\hline
\end{tabular}

niques that had been described before, most notably by the American James Corning (1855-1923) and the German August Bier (1861-1949).

The first direct spinal puncture in a living person is often credited to Corning, who in 1885 injected a cocaine solution into the epidural space at the T11-T12 level of a man who was habituated to masturbation and suffered from 'spinal weakness and seminal incontinence' $[4,5]$. In 1895 , Bier successfully anesthetized the lower body of one of his residents by injecting a cocaine solution into the intrathecal space. Unfortunately, the procedure was complicated by severe headache due to intracranial hypotension lasting for more than 1 week [6].

Bearing the work of Corning and Bier in mind, Sicard started his research on the spine in 1896, when he became an intern at the laboratory of the neurologists Fulgence Raymond (1844-1910) and Edouard Brissaud (18521909) at the famous Hôpital de La Salpetrière. At the be- 
ginning of his project, his goal was 2-fold: (1) to regard the spine from a clinical point of view, rather than from a mere anatomical or physiological perspective and (2) to administer medicinal fluids into the spine, instead of withdrawing cerebrospinal fluid by lumbar puncture [7].

Sicard first experimented on animals. He was able to anesthetize the lower body of several dogs easily by injecting a small amount of cocaine, not between the lumbar vertebrae, as Bier had done, but by using, what has since been known as, the 'caudal route'. Sicard passed a needle through the (first) dorsal sacral foramen to gain access to the sacral roots. Hereby, he left the outermost layer of the meninges intact, carefully confining himself to the epidural space. After his experiments with dogs, Sicard performed similar injections in human cadavers to improve his skill and finally injected patients suffering from pain $[3,7]$.

On April 20, 1901, Sicard presented the data of 9 of his patients during a weekly meeting of the Societé de Biologie in Paris. Two suffered from syphilitic myelopathy, 2 had low back pain and 4 had sciatica. The treatment was painless, safe and (most importantly) successful:

Tous nos malades ont été immédiatement soulagés. Il est vrai que les deux tabétiques n'ont vu leurs douleurs fulgurantes disparaître que pour douze à vingt heures, mais, par contre, la guérison s'est maintenue depuis quatorze jours chez les deux maladies atteints de lumbago, ainsi que dans deux des cas de sciatique rebelle. Les deux autres malades atteints de sciatique sont toujours très soulagés durant deux à trois jours à chaque nouvelle injection [3].

[All our patients were relieved immediately. It is true that the 2 patients with tabes only saw their fierce pains disappear for 12-20 $\mathrm{h}$, but recovery has been maintained for 14 days in the 2 patients with low back pain as well as in 2 resistant cases of sciatica. The 2 other patients with sciatica have been relieved for 2-3 days after each new injection.]

Only a week, after Sicard had presented his data, Fernand Cathelin, who worked as a resident in urology, was quick to come up with similar data. In front of the same audience at the Societé de Biologie, he made a clear statement:

Toute question de priorité étant écartée, nous avons expérimenté, M. Sicard et moi, simultanément et indépendamment l'un de l'autre [8].

[Let's not talk about priority, Mr. Sicard and I, have experimented simultaneously and independently from one another.]

Cathelin also used the caudal approach with cocaine to anesthetize his patients, but unfortunately his results were not as positive as those by Sicard. Four patients that needed inguinal repair were anesthetized only partly. Cathelin suggested he should have increased the dosage. With our current knowledge, we can conclude that Cathelin probably injected 'too low' and should have injected a higher, lumbar level of the spine, in order to anesthetize the inguinal region.

In his $\mathrm{PhD}$ thesis that was published in 1903, Cathelin was far less tactful when it came to priority [9]. In a lengthy argumentation, he left no doubts that he was the first and only one to have introduced the caudal epidural injection. According to Cathelin, Sicard had absolutely 'no right' to claim any priority.

Nous restons donc le premier à avoir expérimenté cette méthode sur l'animal et le seul à avoir fourni un protocole complet, le premier et le seul à en avoir donné un théorie, le premier... [9].

[So we remain the first to have experimented with this method in animals and the only ones who have provided a complete protocol, the first and only to have given a theory, the first to...]

In the years to follow, Sicard would become famous as 'pain doctor'. In particular, during World War I, he performed numerous alcoholizations for painful peripheral nerve injuries, in particular causalgia $[10,11]$. Sicard is also known as the founder of contrast radiology. In 1921, Sicard and Jacques Forestier (1890-1978) made the first epidurogram by injecting contrast fluid in the epidural space, followed by examination of the subarachnoid space and myelography $[12,13]$. Cathelin became chief surgeon at the Hôpital d'Urologie, Paris, and was primarily interested in surgery and related anesthetic techniques, rather than in pain management.

\section{Some Ideas are Quick, Others Slow}

Some innovations in the history of medicine spread quickly. For example, the discovery of ether to anesthetize patients in 1,846 spread across the Atlantic from Boston to Paris and London in only 4 weeks [14]. Other possibly good ideas, on the contrary, travel slowly. Major international publications about the epidural treatment of sciatica appeared only 2-3 decades after the initial descriptions by Sicard and Cathelin.

In 1925, Viner from Montreal also employed the caudal approach but used novocain instead of cocaine [15]. He repeated the injections in patients with sciatica 3-4 times at weekly intervals with good outcome. He wrote thus: 'this method is very effective in giving relief in in- 
tractable (and ordinary) sciatica. In most cases, it restores the patient to his occupation and in practically all cases speedily gives marked relief from pain'. The adjective 'intractable' referred to the often unknown origin of the pain. It should be noted that the herniated disc that is currently known as the most frequent cause of sciatica was not widely known until 1934 by Mixter and Barr [16].

In 1930, Evans reported treating 40 patients with 'idiopathic sciatica' by caudal injection of normal saline and procaine hydrochloride [17]. Sciatica was relieved completely in 24 patients and 'considerable benefit' occurred in 6 patients. Evans was the first to inject large volumes. He demonstrated that injection of $100 \mathrm{ml}$ of fluid into the epidural space at the base of the sacrum caused diffusion of the fluid throughout the spinal canal.

\section{Compound E and the Quest for Evidence}

In the early 1920s, animal research at the Mayo Clinic led to the discovery of cortisone or 'compound E' [18]. Shortly after the World War II, the first patients with rheumatoid arthritis were treated [19]. The results were spectacular, almost like an 'awakening', making corticosteroids the cornerstone of rheumatism treatment ever since. In 1952, Robecchi and Capra, 2 Italian rheumatologists from Torino, speculated that not only rheumatic disease, but low back pain as well as sciatica were also caused by inflammation, an important hypothesis that still holds today. Their first description (in Italian) was of a woman with sciatica, who reported successful pain relief after 'periradicular' infiltration with hydrocortisone of the first sacral nerve root [20]. Hydrocortisone or 'compound $\mathrm{F}$ ' is a steroid with a longer lasting effect that was discovered in the early 1950s. Soon, more articles followed, most of them in French and Italian. Lievre et al. [21] treated 46 patients with sciatica with hydrocortisone. Of these 8 had a very good response, 15 good and 8 mediocre. Goebert et al. [22] were the first to report the use of epidural corticosteroids against sciatica in the United States: 3 injections of procaine and hydrocortisone caused greater than $60 \%$ relief of symptoms in $58 \%$ of patients $(\mathrm{n}=239)$.

The most important uncontrolled trials between 1950 and 1990 are summarized in the table, adapted from Nelson and Landau (table 2) [21-29]. The reader should be aware that the table only shows data from epidural administration of corticosteroids. Intrathecal injections were popular for a short period during the 1960s [30, 31],
Table 2. The most important uncontrolled studies [23]

\begin{tabular}{lrll}
\hline First author, year & n & Study design & $\begin{array}{l}\text { Patients with pain } \\
\text { relief, \%* }\end{array}$ \\
\hline Lièvre, 1953 & 20 & Retrospective & 25 at 3 weeks \\
Brown, 1960 & 20 & Retrospective & 100 at 52 weeks \\
Goebert, 1960 & 239 & Retrospective & 6 at $12-130$ weeks \\
Gardner, 1961 & 113 & Retrospective & 83 at $>12$ weeks \\
Winnie, 1972 & 10 & Prospective & 100 at 2-104 weeks \\
Rosen, 1988 & 40 & Retrospective & 25 at 1-32 weeks \\
Power, 1992 & 16 & Retrospective & 6 at 1 week \\
Bowman, 1993 & 35 & Retrospective & 43 at 12 weeks \\
\hline
\end{tabular}

$*$ Definition of 'pain relief' $=$ excellent + good + moderate + 'not severe'.

but the risk of meningitis has made this approach uncommon in modern pain management. Apart from being uncontrolled, the studies mentioned in the table have various other methodological shortcomings. Most of them are unblinded, contain small numbers of patients and have a retrospective design. However, despite their often poor quality, the older studies contributed to wide acceptance and worldwide use of corticosteroids against sciatica.

The first randomized controlled studies date from the 1970 s and yielded conflicting results. For example, Dilke et al. [32] investigated 100 consecutive patients with sciatica in a randomized blinded trial (epidural corticosteroids vs. cutaneous saline injections). The results were labeled 'striking' - patients who received epidural corticosteroids experienced less pain than controls, needed surgery less often and returned back to work sooner. Snoek et al. [33], on the contrary, showed that 'extradural injection of methyl prednisolone $(80 \mathrm{mg}$ ) is no more effective than a placebo injection in relieving chronic symptoms due to myelographically demonstrable lumbar disc herniation'. A good, consistent positive response to epidural corticosteroids in patients with sciatica has not been described yet.

\section{Current State of the Art}

Over the past few decades, the technique and indications for epidural injections have been changing constantly. A variety of anesthetics (procaine, lidocaine, bupivacaine) as well as a number of glucocorticoids (hydrocortisone, methylprednisolone, triamcinolone) have been used. The caudal approach, originally described by 
Sicard and Cathelin, has largely been replaced by interlaminar and transforaminal injections that are usually given under fluoroscopic guidance. With the interlaminar approach, the needle is placed in the posterior epidural space comparable to epidural catheter placement in surgery. With the transforaminal approach, the needle is placed in one of the intervertebral foramina, where the spinal nerve root exits the spinal canal. Most pain physicians prefer transforaminal injections, as at least one study showed superiority compared to the interlaminar technique with regard to pain relief and functional status [34].

Huge numbers of epidural corticosteroids are administered every year for a variety of spine conditions manifesting with back pain and/or sciatica: herniated disk, end-stage degenerative disc disease, spinal or foraminal stenosis and failed back surgery. The patients have only 2 major concerns about the injections: 'do they work?' and 'are they safe?' The respective answers are 'no' and 'yes'.

The evidence in favor of epidural injections against sciatica is hardly convincing. Pinto et al. [35] analyzed the data of 23 trials (since 1984). The overall quality of evidence according to the GRADE classification was rated as high [36]. The pooled results showed a significant, although small, effect of epidural corticosteroid injections compared with placebo for leg pain in the short term (mean difference -6.2 on a $0-100$ visual analogue pain scale (95\% CI -9.4 to -3.0$)$ ) and also for disability in the short term (mean difference -3.1 (95\% CI -5.0 to -1.2$)$ ). 'Short term' was defined as 2-12 weeks. The long-term (>3 months) pooled effects were smaller and not statistically significant.

Several studies have been conducted with regard to side effects and safety of epidural steroid injections [3740]. Common side effects include nausea, headache, dizziness, vasovagal attacks and flushing of the face. Unintentional dural puncture might cause post-spinal tap headache. Abram and O'Connor [41] looked at 53 series of descriptions of epidurals (66,000 patients). They only found 2 cases of epidural abscess, 1 case of bacterial meningitis and 1 case of aseptic meningitis following epidural steroid injections. Other complications reported in the literature are Cushing's syndrome due the use of corticosteroids, dural leak in case of an accidental intrathecal puncture, air embolus and allergy. Severe complications, including spinal cord infarction and cerebral ischemia, are very rare and have only been described as case reports [42-45]. Several cases of fungal meningitis have been reported from the injection of contaminated compound methylprednisolone acetate [46].
To address concerns related to medication-related risks, the US Food and Drug Administration (FDA) created its Safe Use Initiative (SUI) in 2009 to establish and facilitate public and private collaborations within the healthcare community. The SUI facilitated the organization with a multidisciplinary expert working group created to review the existing evidence regarding neurologic complications associated with epidural corticosteroid injections and produce consensus procedural clinical considerations aimed at enhancing the safety of these injections. Seventeen clinical statements/considerations aimed at improving safety came out that should lead to a reduction of the number of neurologic injuries following epidural corticosteroid injections of both neck and lumbar spine. The list included a statement about the potential hazard of cervical injections and a recommendation that all lumbar and cervical injections should be performed under radiological guidance $[47,48]$.

Despite the rarity of severe complications, the FDA issued a letter in April 2014, warning about 'loss of vision, stroke, paralysis and death' as a result of epidural corticosteroid injections [49]. The FDA advice was later countered by a number of experts in the field, who requested the FDA to modify its statement $[50,51]$. In their opinion, the FDA should spread an evidence-based warning, emphasizing the off-label use of epidural steroids, which can cause rare, but serious neurologic problems following cervical and thoracic injections and also an increased risk with lumbar injections when performed without appropriate precautions.

The risks associated with epidural steroid injections were discussed at a meeting of the FDA's Anesthetic and Analgesic Drug Products Advisory Committee in November 2014. Some committee members noted that the current class warning should be removed for lumbar epidural injections; however, others stated that the class warning should be continued and removal at this point would be misleading and falsely indicative of evidence of safety [52].

\section{Conclusions}

We identified 5 successive stages in the development of epidural corticosteroids against sciatica: (1) pioneer stage, (2) globalization, (3) introduction of corticosteroids, (4) uncontrolled trials and (5) randomized controlled trials.

It is interesting that the first descriptions came from 2 different laboratories in Paris at the same time. This 
seems too much of a coincidence. In our opinion, whether Sicard or Cathelin heard must have 'heard it through the grapevine'. The fact that there are 2 pioneers is hardly a surprise as most scientific discoveries can rarely be attributed to a single individual. The dispute between Sicard and Cathelin is just one of a long list of claims and conflicts about originality from the history of medicine [53].

Contrary to other ideas in the history of medicine, it took a long time for the epidural injections to spread around the world. This might have to do with language (French) or with the fact that the effects of caudal injections with cocaine were just not spectacular enough.

The introduction of corticosteroids in the 1950s as a panacea against all kind of pain conditions and a number of uncontrolled, positive clinical trials during the 1960s and 1970 s contributed to wide acceptance and popularization of epidural corticosteroids against back pain and sciatica. However, the popularity of the injections seems irrational to us. The scientific proof that epidural corticosteroids are effective against back pain and sciatica is hardly convincing. More prospective data in selected populations, for example acute patients only, are needed in support of epidural corticosteroids. There are also important safety issues that have been addressed by the FDA in 2014. However, severe complications of lumbar epidural injections against back pain and sciatica are very rare.

\section{Disclosure Statement}

The authors have no conflicts of interest to disclose.

\section{References}

1 Bicket MC, Chakravarthy K, Chang D, Cohen SP: Epidural steroid injections: an updated review on recent trends in safety and complications. Pain Manag 2015;5:129-146.

2 Manchikanti L, Falco FJ, Singh V, et al: Utilization of interventional techniques in managing chronic pain in the Medicare population: analysis of growth patterns from 2000 to 2011. Pain Physician 2012;15:E969-E982.

3 Sicard MA: Les injections médicamenteuses extradurales par voie sacrococcygienne. C R Seances Soc Biol Fil 1901;53:396.

4 Corning JL: Spinal anaesthesia and local medication of the cord. N Y Med J 1885;42:483485.

5 Gorelick PB, Zych D: James Leonard Corning and the early history of spinal puncture. Neurology 1987;37:672-674.

6 Bier A: Versuche über cocainisirung des rückenmarkes. Deutsche Zeitschrift für Chirurgie 1899;51:361-369.

7 Sicard JA: Le Liquide céphalo-rachidien, recherches expérimentales et cliniques. Paris, Masson et cie., 1900

8 Cathelin F: Une nouvelle voie d'injection rachidienne: méthode des injections épidurales par le procédé du canal sacre - applications à l'homme. Compt Rend Soc de Biol 1901;53: 452-453.

9 Cathelin F: Les Injections Epidurales et Leurs Applications Dans les Maladies des Voies Urinaires. Paris, Baillière et fils, 1903.

10 Steimlé R: Jean A. Sicard (1872-1929). J Neurol 2013;260:1946-1947.

11 Koehler PJ: Lessons from peripheral nerve injuries; causalgia in particular; in Fine E (ed): History Course. Lessons from War. San Diego, American Academy of Neurology, 2013.

12 Sicard JA, Forestier J: Méthode radiographique d'exploration de la cavité épi- durale par le Lipiodol. Rev Neurol 1921;2: 1264.

13 Sicard JA, Forestier J: Roentgenologic exploration of the central nervous system with iodised oil (lipiodol). Archives Neur Psych 1926;16:420-434.

14 Gawande A: Slow Ideas. The New Yorker, 2013.

15 Viner N: Intractable sciatica. The sacral epidural injection; an effective method of giving relief. Can Med Assoc J 1925;15:630-634.

16 Mixter WJ, Barr JS: Rupture of the intervertebral disc with involvement of the spinal canal. N Engl J Med 1934;211:210-215.

17 Evans W: Intrasacral epidural injection in the treatment of sciatica. Lancet 1930;216:12251228.

18 Clapsattle H: The Doctors Mayo, ed 2. Rochester, Mayo Clinic Press, 1969, p 376.

19 Kendall EC: Some observations on the hormone of the adrenal cortex designated compound E. Proc Staff Meet Mayo Clin 1949;24: 298-301.

20 Robecchi P, Capra AL: L'idrocortisone (composto F), prime esperienze cliniche in campo reumatologico. Minerva Med 1952;2:12591263.

21 Lièvre JA, Bloch-Michel H, Pean G, et al: L'hydrocortisone en injection locale. Rev Rhum Mal Osteoartic 1953;20:310-311.

22 Goebert HW Jr, Jallo SJ, Gardner WJ, et al: Sciatica: treatment with epidural injections of procaine and hydrocortisone. Cleve Clin Q 1960;27:191-197.

23 Nelson DA, Landau WM: Intraspinal steroids: history, efficacy, accidentality, and controversy with review of United States Food and Drug Administration reports. J Neurol Neurosurg Psychiatry 2001;70:433443.
24 Brown JH: Pressure caudal anesthesia and back manipulation. Conservative method for treatment of sciatica. Northwest Med 1960; 59:905-909.

25 Winnie AP, Hartman JT, Meyers HL Jr, et al: Pain clinic. II. Intradural and extradural corticosteroids for sciatica. Anesth Analg 1972; 51:990-999.

26 El-Khoury GY, Ehara S, Weinstein JN, et al: Epidural steroid injection: a procedure ideally performed with fluoroscopic control. Radiology 1988;168:554-557.

27 Rosen CD, Kahanovitz N, Bernstein R, et al: A retrospective analysis of the efficacy of epidural steroid injections. Clin Orthop Relat Res 1988;228:270-272.

28 Power RA, Taylor GJ, Fyfe IS: Lumbar epidural injection of steroid in acute prolapsed intervertebral discs. A prospective study. Spine (Phila Pa 1976) 1992;17:453-455.

29 Bowman SJ, Wedderburn L, Whaley A, et al: Outcome assessment after epidural corticosteroid injection for low back pain and sciatica. Spine (Phila Pa 1976) 1993;18:13451350.

30 Gardner WJ, Goebert HW Jr, Sehgal AD: Intraspinal corticosteroids in the treatment of sciatica. Trans Am Neurol Assoc 1961;86:214-215.

31 Sehgal AD, Gardner WJ, Dohn DF: Pantopaque 'arachnoiditis' treatment with subarachnoid injection of corticosteroids. Cleveland Clinic Quarterly 1962;29:177-188.

32 Dilke TF, Burry HC, Grahame R: Extradural corticosteroid injection in management of lumbar nerve root compression. Br Med J 1973;2:635-637.

33 Snoek W, Weber H, Jorgensen B: Double blind evaluation of extradural methyl prednisolone for herniated lumbar discs. Acta Orthop Scand 1977;48:635-641. 
34 Schaufele MK, Hatch L, Jones W: Interlaminar versus transforaminal epidural injections for the treatment of symptomatic lumbar intervertebral disc herniations. Pain Physician 2006;9:361-366.

35 Pinto RZ, Maher CG, Ferreira ML, et al: Epidural corticosteroid injections in the management of sciatica: a systematic review and metaanalysis. Ann Intern Med 2012;157:865-877.

36 Atkins D, Best D, Briss PA, et al; GRADE Working Group: Grading quality of evidence and strength of recommendations. BMJ 2004; 328:1490.

37 Botwin KP, Gruber RD, Bouchlas CG, et al: Complications of fluoroscopically guided transforaminal lumbar epidural injections. Arch Phys Med Rehabil 2000;81:1045-1050.

38 Epstein NE: The risks of epidural and transforaminal steroid injections in the Spine: commentary and a comprehensive review of the literature. Surg Neurol Int 2013;4(suppl 2):S74-S93.

39 El-Yahchouchi CA, Plastaras CT, Maus TP, et al: Adverse event rates associated with transforaminal and interlaminar epidural steroid injections: a multi-institutional study. Pain Med 2015, Epub ahead of print.

40 Plastaras C, McCormick ZL, Garvan C, et al: Adverse events associated with fluoroscopi- cally guided lumbosacral transforaminal epidural steroid injections. Spine J 2015;15: 2157-2165.

41 Abram SE, O'Connor TC: Complications associated with epidural steroid injections. Reg Anaesth 1996;21:149-162.

42 Kennedy DJ, Dreyfuss P, Aprill CN, Bogduk $\mathrm{N}$ : Paraplegia following image-guided transforaminal lumbar spine epidural steroid injection: two case reports. Pain Med 2009;10: 1389-1394.

43 Somayaji HS, Saifuddin A, Casey AT, Briggs TW: Spinal cord infarction following therapeutic computed tomography-guided left L2 nerve root injection. Spine (Phila Pa 1976) 2005;30:E106-E108.

44 Deshpande DM, Krishnan C, Kerr DA: Transverse myelitis after lumbar steroid injection in a patient with Behcet's disease. Spinal Cord 2005;43:735-737.

45 Lyders EM, Morris PP: A case of spinal cord infarction following lumbar transforaminal epidural steroid injection: MR imaging and angiographic findings. AJNR Am J Neuroradiol 2009;30:1691-1693.

46 Malani AN, Vandenberg DM, Singal B, et al: Magnetic resonance imaging screening to identify spinal and paraspinal infections associated with injections of contaminated methylprednisolone acetate. JAMA 2013;309: 2465-2472.

47 Rathmell JP, Benzon HT, Dreyfuss P, et al: Safeguards to prevent neurologic complications after epidural steroid injections: consensus opinions from a multidisciplinary working group and national organizations. Anesthesiology 2015;122:974-984.

48 Benzon HT, Huntoon MA, Rathmell JP: Improving the safety of epidural steroid injections. JAMA 2015;313:1713-1714.

49 http://www.fda.gov/Drugs/DrugSafety/ ucm394280.htm.

50 Manchikanti L, Candido KD, Singh V, et al: Epidural steroid warning controversy still dogging FDA. Pain Physician 2014;17:E451-E474.

51 Candido KD, Knezevic NN, Chang-Chien GC, Deer TR: The Food and Drug Administration's recent action on April 23, 2014 failed to appropriately address safety concerns about epidural steroid use. Pain Physician 2014;17:E549-E552.

52 http://www.fda.gov/downloads/AdvisoryCommittees/CommitteesMeetingMaterials/ Drugs/AnestheticAndAnalgesicDrugProductsAdvisoryCommittee/UCM429414.pdf.

53 Merton RK: Priorities in scientific discovery: a chapter in the sociology of science. Am Sociol Rev 1957;22:635-659. 